\title{
A pilot newborn screening program for Mucopolysaccharidosis type I in Taiwan
}

\author{
Shuan-Pei Lin ${ }^{1,2,6,7 \dagger}$, Hsiang-Yu Lin 1,2,6,7,10†, Tuen-Jen Wang ${ }^{3,8}$, Chia-Ying Chang ${ }^{9}$, Chia-Hui Lin ${ }^{3}$, Sung-Fa Huang ${ }^{3,8}$, \\ Chia-Chen Tsai ${ }^{1}$, Hsuan-Liang Liu ${ }^{4}$, Joan Keutzer ${ }^{11}$ and Chih-Kuang Chuang ${ }^{1,4,5^{*}}$
}

\begin{abstract}
Background: Mucopolysaccharidosis type I (MPS I) is a genetic disease caused by the deficiency of a-L-iduronidase (IDUA) activity. MPS I is classified into three clinical phenotypes called Hurler, Scheie, and Hurler-Scheie syndromes according to their clinical severity. Treatments for MPS I are available. Better outcomes are associated with early treatment, which suggests a need for newborn screening for MPS I. The goal of this study was to determine whether measuring IDUA activity in dried blood on filter paper was effective in newborn screening for MPS I.

Methods: We conducted a newborn screening pilot program for MPS I from October 01, 2008 to April 30, 2013. Screening involved measuring IDUA activity in dried blood spots from 35,285 newborns using a fluorometric assay.

Results: Of the 35,285 newborns screened, 19 did not pass the tests and had been noticed for a recall examination. After completing further recheck process, 3 were recalled again for leukocyte IDUA enzyme activity testing. Two of the three had deficient leukocyte IDUA activity. Molecular DNA analyses confirmed the diagnosis of MPS I in these two newborns.

Conclusions: It is feasible to use the IDUA enzyme assay for newborn screening. The incidence of MPS I in Taiwan estimated from this study is about 1/17,643.
\end{abstract}

Keywords: Mucopolysaccharidosis type I, a-L-iduronidase, Dried blood spots, Newborn screening

\section{Introduction}

The mucopolysaccharidoses (MPS) are a group of inherited diseases known as lysosomal storage disorders. Each MPS is caused by the deficiency of a different enzyme that catalyzes the stepwise degradation of glycosaminoglycans (GAG; mucopolysaccharides) in lysosomes. Mucopolysaccharidosis type I (MPS I) is inherited in an autosomal-recessive fashion and caused by deficiency of $\alpha$-L-iduronidase (IDUA; EC 3.2.1.76) activity and progressive accumulation of its substrates, partially degraded dermatan and heparin sulfate, in lysosomes. The accumulation of dermatan and heparan sulfate in lysosomes trigger changes in cellular metabolism that lead to tissue and organ damage and the signs and symptoms of MPS I. Patients with MPS I can have coarse facial features,

\footnotetext{
*Correspondence: cck@ms1.mmh.org.tw

${ }^{\dagger}$ Equal contributors

'Division of Genetics and Metabolism, Department of Medical Research, Mackay Memorial Hospital, Taipei, Taiwan

${ }^{4}$ Institute of Biotechnology, National Taipei University of Technology, Taipei, Taiwan

Full list of author information is available at the end of the article
}

developmental delay and decline, gibbus deformity, hepatosplenomegaly, cardiac valve disease, umbilical and inguinal hernias, joint restriction, upper airway complications, sleep apnea, recurrent otitis media, and premature death. MPS I is classified into three clinical phenotypes called Hurler, Scheie, and Hurler-Scheie syndromes according to their clinical severity [1-3].

Treatment for MPS I involves supportive and symptom-based treatment and disease-specific treatments that address the underlying cause of the disease. Disease-specific treatments to replace IDUA activity include laronidase enzyme replacement therapy for the non-neurologic manifestations of MPS I patients [4-12] and bone marrow and hematopoietic stem cell transplantation for Hurler syndrome patients [13-16]. de Ru et al. reported that enzyme replacement therapy (ERT) can result in good clearance of GAGs from many tissues and can significantly ameliorate several symptoms [12]. However, some of the clinical symptoms of MPS I are irreversible and bone marrow and hematopoietic stem cell

\section{Biomed Central}

(C) 2013 Lin et al.; licensee BioMed Central Ltd. This is an Open Access article distributed under the terms of the Creative Commons Attribution License (http://creativecommons.org/licenses/by/2.0), which permits unrestricted use, distribution, and reproduction in any medium, provided the original work is properly cited. 
transplantation must precede developmental decline [14]. Thus, early diagnosis is crucial and positively related to the response of MPS I patients to diseasespecific therapies. Data from siblings who began treatment at different ages suggest that initiation of laronidase treatment in infancy, before the development of significant disease manifestations, may improve outcome with respect to coarse facial features, musculoskeletal disease, cardiac valve disease [17] and brain MRI abnormalities [18]. These results suggest that early diagnosis of MPS I through newborn screening may improve the prognosis of patients with MPS I.

MPS I patients were $5.3 \%$ of the MPS patients diagnosed in Taiwan from 1984 to 2004. A Taiwanese MPS I birth prevalence of 0.11 per 100,000 live births was estimated using diagnostic frequency data, population data, and a review of all MPS I patient's medical records [19]. This estimated birth prevalence is lower than expected, but may reflect undiagnosed and misdiagnosed MPS I patients. We conducted a pilot MPS I newborn screening program in Taiwan from October 1, 2008 through April 30, 2013. The objectives of the study were to determine whether measuring IDUA activity in dried blood on filter paper was effective in newborn screening for MPS I and to determine the birth prevalence of MPS I in Taiwan.

\section{Materials and methods}

\section{Dried blood spot sample preparation}

Dried-blood spot (DBS) samples were prepared using the National Committee for Clinical Laboratory Standards protocol (NCCLS standard LA4-A4), "Blood Collection on Filter Paper for Neonatal Screening Program" $[20,21]$. Blood samples were collected by heel puncture on the third day of life. Drops of blood were spotted directly on filter paper (ToYo PKU No.545, Japan), and dried at least 4 hours at room temperature. DBS samples were stored at $4^{\circ} \mathrm{C}$ in zipper-lock plastic bags. IDUA activity was measured in two 3.2-mm-diameter disks from each DBS. From October 1, 2008 to April 30, 2013, a total of 35,285 samples from newborns were collected from our hospital. DBS samples from two patients with a confirmed diagnosis of MPS I (before and after ERT) and 4 MPS I obligate carriers were also included in this study. All samples were collected following written informed consent.

\section{Chemicals}

All chemicals were obtained from Sigma Co., and the substrate, 4-methylumbelliferyl- $\alpha$-L-iduronide, was purchased from Toronto Research Chemicals in Canada.

\section{Control DBS filter papers}

Blood collected in EDTA from normal volunteers and pooled was used to make a normal control $(\mathrm{C} 1, \mathrm{n}=20)$ and an inactivated control $(\mathrm{C} 2, \mathrm{n}=20)$. Inactivated control DBS were placed in a $50^{\circ} \mathrm{C}$ oven for 96 hours to degrade IDUA activity. These control dried blood spots on filter paper (DBFPs) were used for assay quality control.

\section{IDUA enzyme assay}

A modification of the method published by Chamoles et al. was used [22,23]. Elution buffer contains $50 \mathrm{mmol} / \mathrm{L}$ formate buffer $(\mathrm{pH} 2.8)$ and $3.57 \mu \mathrm{mol} / \mathrm{L} \mathrm{d}$-saccharic acid-1, 4-lactone. A reaction mixture contained the elute solution and the substrate (4-methylumbelliferyl- $\alpha$-Liduronide) in a 2:1 ratio $(\mathrm{v} / \mathrm{v})$. One $3.2 \mathrm{~mm}$ disc, which contains approximate $3.55 \mu \mathrm{L}$ of blood was punched from each DBS using a Wallac DBS puncher (Perkin Elmer, Inc., USA), and placed into 96-well black microtiter plate (F 96, Nunc, Denmark). Thirty $\mu \mathrm{L}$ of reaction mixture (two parts elution buffer and 1 part substrate) was added to each well. The plate was covered well with foil to avoid influences from light, air, and humidity. The plate was incubated at $37^{\circ} \mathrm{C}$ in an orbital shaker at $250 \mathrm{rpm}$ (Medclub Scientific CB-2201) for $20 \mathrm{~h}$. One-hundred and fifty $\mu \mathrm{L}$ of glycine-carbonate buffer (stop solution) was added to each well and the plate was kept at room temperature for 30 minutes to stop the reaction. The fluorescence of the enzyme product, 4-methylumbelliferone (4-MU), was measured by using a microplate Fluorometer (Victor $2 \mathrm{D}^{\circ}$ Neonatal Fluorometer, Perkin Elmer) with excitation $360 \mathrm{~nm}$ and emission $450 \mathrm{~nm}$. The filter paper did not need to be removed during the analysis. The fluorescence readings were corrected for blanks, and the results were compared with the fluorescence from a 4-MU calibration curve. IDUA enzymatic activities were expressed as micromoles of substrate hydrolyzed per liter of blood per $20 \mathrm{~h}$.

\section{Calibration curve}

A calibration curve was made fresh each time the test was performed. A $50 \mathrm{mM} 4-\mathrm{MU}$ stock solution was prepared in DMSO. A $0.02 \mu \mathrm{M}$ working standard solution was first prepared in deionized water, and diluted serially to generate seven calibrators at concentrations of 0.02 , $0.008,0.0032,0.00128,0.000512,0.0002048 \mu \mathrm{M}$. Water was used as a blank. The regression analysis $\left(r^{2}\right)$ of the calibration curve (fluorescence reading vs. concentrations of 4-MU calibrations) was excellent $\left(r^{2}=0.991\right)$.

\section{Results}

In the study, forty samples were run and calculated for within-run and between-run precisions (Coefficient of Variance; CV\%). All the 40 samples were run in 6 consecutive replicates for within-run analysis, and a duplicate analysis of each sample $(n=40)$ was performed on 6 different days sequentially. The within-run and betweenrun precisions of DBFP fluorescence enzyme assay were $9.35 \%$ and $11.99 \%$, respectively. In order to ensure the 
stability and the accuracy of fluorescence enzyme assay in DBFP, the within-run and between-run precisions of control DBFPs ( $\mathrm{C} 1$ and $\mathrm{C} 2$ ) were also evaluated, which were $7.11 \%$ and $8.57 \%$ for $\mathrm{C} 1$, as well as $9.16 \%$ and $8.70 \%$ for C2, respectively. The overall IDUA activities in average of $\mathrm{C} 1$ and $\mathrm{C} 2$ were $54.48( \pm 4.51)$ and 31.55 $( \pm 2.92) \mu \mathrm{mol} / \mathrm{L}$ blood*20 h.

The reference values of IDUA activities using DBFP fluorescence enzyme assay were $9.03-69.52 \mu \mathrm{mol} / \mathrm{L}$ blood $20 \mathrm{~h}($ Mean $\pm \mathrm{SD}=39.58 \pm 15.12 ; \mathrm{n}=2173)$ (Figure 1 ), and the samples showed a normal distribution (Kolmogorov-Smimov $Z=7.703$ ) analyzed with the SPSS for Windows 11.0 program (SPSS Inc., Chicago, IL, USA) (Figure 2). For the confirmed MPS I patients before ERT $(n=2)$, the IDUA activities were both less than $5 \%$ of the normal population, and ranged from 0.29 to $0.95 \mu \mathrm{mol} / \mathrm{L}$ blood $20 \mathrm{~h}$. The IDUA activities obtained from the same patients who have received ERT by weekly infusion $(n=2)$ showed significantly elevated about ten-fold increases, ranged from 5.53 to $6.77 \mu \mathrm{mol} / \mathrm{L}$ blood $20 \mathrm{~h}$. The IDUA activities of the carriers who are the parents of the confirmed MPS I patients $(n=4)$ were slightly reduced in concentrations when comparing with the normal values, ranged from 9.40 to $19.82 \mu \mathrm{mol} / \mathrm{L}$ blood* $20 \mathrm{~h}$.

In this MPS I newborn screening project, a total of 35,285 newborns were analyzed. In those, 58 newborns had IDUA activity less than $9.03 \mu \mathrm{mol} / \mathrm{L}$ blood*20 h at the first screening test. Most of them $(n=39)$ were exclusive and their data showed normal instead after a second rechecked analysis with the original DBS samples.
The other 19 infants did not pass the tests and had been noticed for a recall examination. All 19 neonates (recalled rate $=0.054 \%$ ) had completed the further rechecked process, and only three infants still had IDUA activities in DBFP lower than $9.03 \mu \mathrm{mol} / \mathrm{L}$ blood*20 h. In order to confirm the diagnosis of those subjects, a series of tests including urine GAG quantification (DMB/CRE ratio), urinary GAG two-dimensional electrophoresis (2-D EP), leukocyte IDUA enzymatic assay, and molecular DNA analysis had been arranged. All the methods described previously $[24,25]$ or from literatures reported elsewhere [26]. The results of the above confirmative methods showed that 2 infants had marked deficiency of IDUA activities were typical of MPS I patients (less than $5 \%$ of the reference values, 6.8$37.0 \mu \mathrm{mol} / \mathrm{g}$ protein $/ \mathrm{hr}$ ), and another that showed definitely reduction in IDUA activity might be a carrier $(3.5 \mu \mathrm{mol} / \mathrm{g}$ protein $/ \mathrm{hr})$. The urinary DMB ratios of the 3 infants were all normal comparing to the reference values of newborn $(44.6 \pm 23.7 \mathrm{mg} / \mathrm{mmol}$ creatinine). The 2-D EP results showed a distinct dermatan sulfate but a faint heparan sulfate pattern in the 2 affected infants and another (carrier suspected) was normal.

The molecular DNA analysis was demonstrated on the 2 highly suspicious MPS I infants and their parents based on the methods reported by Sun et al. [27] and Wang et al. [28]. In the study, the PCR primer sequences and PCR conditions were modified and listed in Table 1. PCR products were purified and sequenced using $A B I$ Prism 3730 DNA sequencer (Applied Biosystems). All

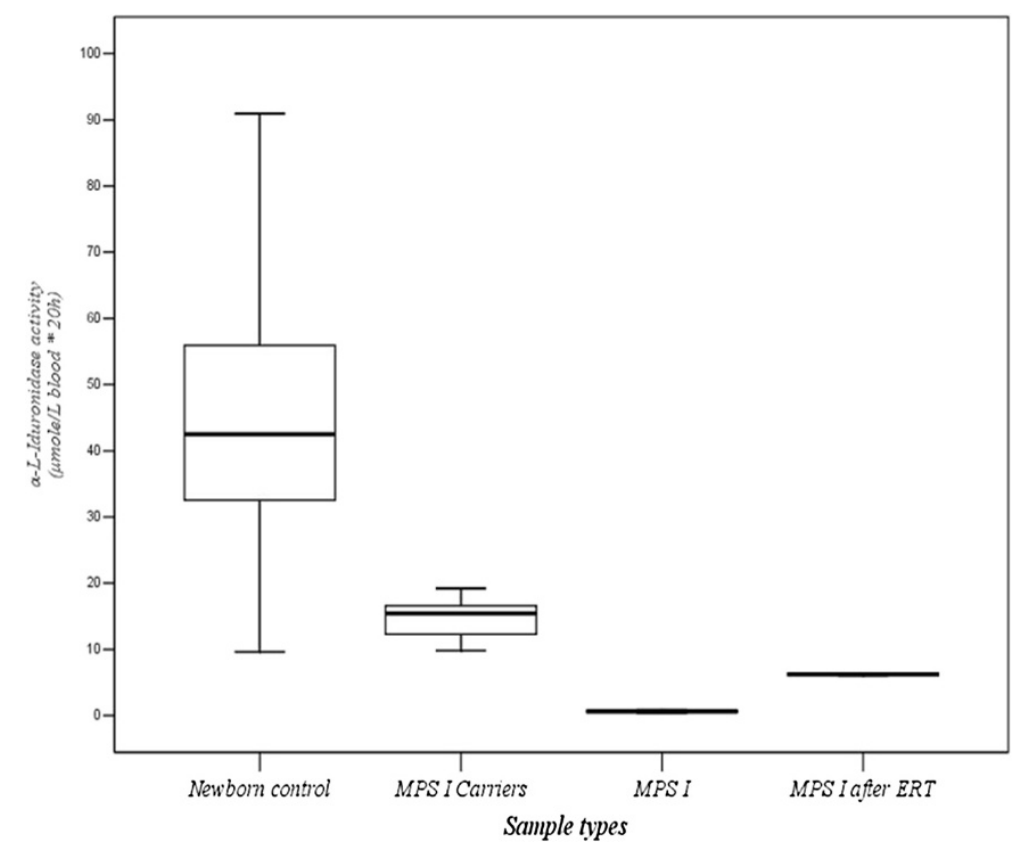

Figure 1 The reference values of IDUA activities in newborn control $(n=35,285)$, MPS I carriers $(n=4)$, confirmed MPS I patients $(n=2)$, and the same patients received ERT. 


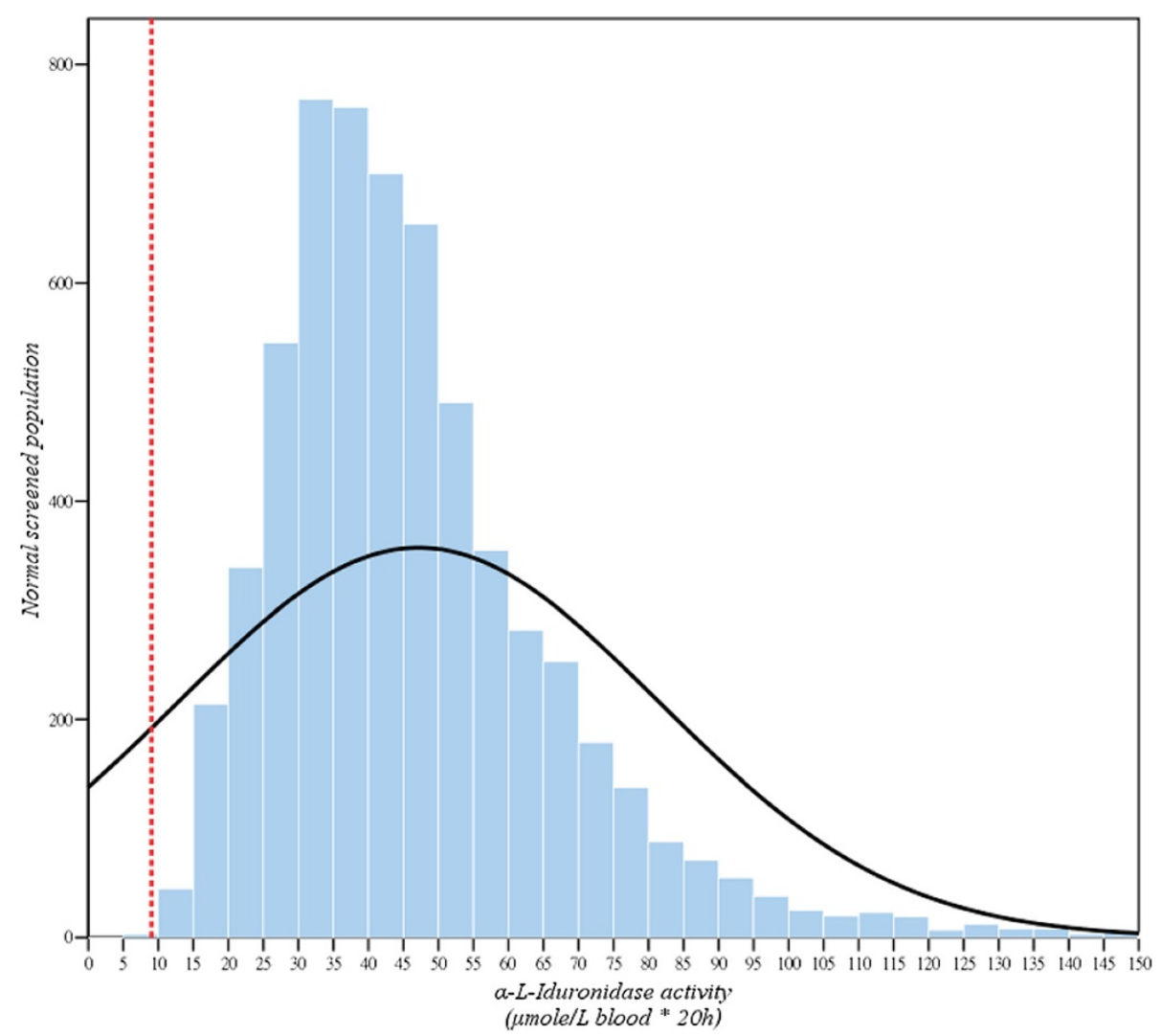

Figure $\mathbf{2}$ The sampling to determine the reference values of IDUA activities in newborn control showed a normal distribution (Kolmogorov-Smimov Z = 7.703).

amplified fragments flanking exons were analyzed to identify variations. Mutations were further verified by restriction analysis of PCR products. Two point mutations were identified in the infant A confined as c.303 G > A (R105Q) that inherited from father/ c.484 G > A (R162K) that inherited from mother. For the infant $B$, the point mutations were also identified and confined as c.344 G $>\mathrm{T}$ (D119Y) inherited from father/ c.99 T > G (H33Q) from mother. All sequence changes were confirmed by restriction enzyme testing on a second PCR product, and the restriction enzyme tests for 4 known mutations in both MPS I patients were listed in Table 2. Molecular genetic testing of IDUA to determine carrier status was performed to both parents of infant $\mathrm{C}$ who was highly suspected to be an MPS I carrier.

\section{Discussion and conclusion}

The reported birth incidence of MPS I in Taiwan (0.11 per 100,000 live births) is equivalent to the prevalence rate in UK published by Murphy et al. [29], and about one tenth of the prevalence reported by Moore et al. [30]. The overall incidence of MPS is estimated to be 1 in 10,000 22,500 births in Europe [1-3,31], and MPS I is by far the relatively rare type. Nelson et al. had published and estimated an incidence of 1 in 76,000 for Hurler syndrome in Northern Ireland, which was proposed to be higher than previously recorded from Lowry and Renwick in 1971 [32,33]. Murphy et al. reported that the birth incidence was 1 in 26,206 with a carrier frequency of 1 in 81 [29], which is nearly three-fold higher than that reported by Nelson. A more recently published report by Scott, et al. showed a higher frequency of MPS I (1 in 35,700) in Washington State, USA [34] which was 3 -fold greater than the prevalence estimated from clinical studies $[31,35]$. Based on the results in this study, the actual incidence of MPS I in Taiwan is about 1 in 17,643 births, and indicates that there are approximately 10 to 12 new patients to be born each year in Taiwan. For early detection purpose, making early diagnosis is extremely valuable, and thus giving them early therapy can help saving lives and preventing brain damage or other health problems.

In the past few years, many screening methods have been proposed for MPS I newborn screening purposes, including immunochemistry assay [36], tandem mass spectrometry method [37-39], and fluorescent enzymatic assay $[22,23]$. In those, the developments of multiplex assay by using tandem mass spectrometry newborn 
Table 1 PCR primer sequences, amplicon length and PCR reaction temperature

\begin{tabular}{|c|c|c|c|}
\hline Exon & Primer sequence & Amplicon length (bp) & Annealing temperature $\left({ }^{\circ} \mathrm{C}\right)$ \\
\hline \multirow[t]{2}{*}{1} & F:5'-CCGCAGTCCCGAGCAC-3' & 277 & 60 \\
\hline & R:5'-GCTCCGGTCTCTGAAGCTCT-3' & & \\
\hline \multirow[t]{2}{*}{2} & F: 5'-CCCTCGTCTTACTGCTGCTG-3' & 401 & 60 \\
\hline & R: 5'TCCCATCTGTGCCTCTGTAA-3' & & \\
\hline \multirow[t]{2}{*}{3,4} & F: 5'-CATACCAGGCCTTCATAGGG-3' & 708 & 58 \\
\hline & R: 5'CCAACCTATCCCTTGTCACC-3' & & \\
\hline \multirow[t]{2}{*}{5} & F: 5'-CATCACCTTGCACCCTCC-3' & 273 & 60 \\
\hline & R: 5'-CGTCTACACCTGCCCTGG-3' & & \\
\hline \multirow[t]{2}{*}{6} & F: 5'-CCGCTCATCCCCAGGGCAGGTGTA-3' & 301 & 60 \\
\hline & R: 5'-ACAGCGGCTGAGGGCGCAGAACAC-3' & & \\
\hline \multirow[t]{2}{*}{7} & F: 5'-CATCTCCCTCCACAGGAAGGTG-3' & 500 & 60 \\
\hline & R: 5'-GGTAGCTCAGGAAGGCATTGTC-3' & & \\
\hline \multirow[t]{2}{*}{8} & F: 5'-TTCCTCCCGAGACGGGACAGGCGA-3' & 437 & 60 \\
\hline & R: 5'-CTCCCCTTGGTGAAGGAGTC-3' & & \\
\hline \multirow[t]{2}{*}{9} & F: 5'-TGGGGACTCCTTCACCAAGGGGAG-3' & 370 & 60 \\
\hline & R: 5'-CAGAGCCCCAGCGGGGCCAGAGAC-3' & & \\
\hline \multirow[t]{2}{*}{10} & F: 5'-ATCTACGCGAGCGACGAC-3' & 470 & 60 \\
\hline & R: 5'-GGTCCTCAGGGTTCTCCAG-3' & & \\
\hline \multirow[t]{2}{*}{11} & F: 5'-GTGTGGGTGGGAGGTGGAGCGGTG-3' & 302 & 60 \\
\hline & R: 5'-AGGGAAGGGCTGTGAGGCGTCGG-3' & & \\
\hline \multirow[t]{2}{*}{12} & F: 5'-GCTITTGCTGGTGCACGTGT-3' & 295 & 60 \\
\hline & R: 5'-AAGTGGCCCGAGTGACCGCAT-3' & & \\
\hline \multirow[t]{2}{*}{13,14} & F: 5'-CCTAGGGGACATGAGATGGA-3' & 814 & 58 \\
\hline & R: 5'-CGGGGTTTACCCTTGGAG-3' & & \\
\hline
\end{tabular}

screening for detectable congenital metabolic diseases, particularly the lysosomal storage diseases (LSD) is thought to be the main stream worldwide in the future. However, those tandem mass assays still have many obstacles to overcome, such as the high-priced instrumentation, unstable substrate and commercially unavailable in part, time-consuming procedures, complexity, and high total cost. The immunochemistry assay using DBFP is another issue commonly used for LSD newborn screening purposes; however, the specificity and the purity of an antibody may affect the ability between antigen and antibody conjugation. Additionally, a false-negative result may be produced due to dysfunction of the detectable antigen (enzyme). In this study, the determination of IDUA activity in DBFP using fluorescence enzyme assay is a secure method for MPS I diagnosis. The DBS fluorescence enzyme assay has many advantages including simple performance, cost effectiveness, high sensitivity and high specificity, high throughput, and limited false positive detection. A diagnostic algorithm for MPS I is provided in Figure 3. The first or a further second testing on the original DBFP sample is accomplished that may rule out the false

Table 2 Restriction enzyme test for 4 known mutations in MPS I patients

\begin{tabular}{|c|c|c|c|c|}
\hline Patients & Mutation & Primers & Restriction enzyme & Fragment size (bp) \\
\hline Infant A & R105Q & F: 5'-CCTTCTGCAGGGGGTCCACTGT-3' & Bsr Gl & $N: 286$ \\
\hline Infant A-father & (exon3) & R: 5'-CAAACCCTGGAACACAGGAG-3' & & M: $286+262+24$ \\
\hline Infant A & R162K & F: 5'-ACCCACCTGGACGGGTACCGG-3' & Apo I & $\mathrm{N}: 357$ \\
\hline Infant A-mother & (exon4) & R: 5'-TGCGCTCGCCCACCGATGAAT-3' & & M: $357+339+18$ \\
\hline Infant B & D119Y & F: 5'-CATACCAGGCCTTCATAGGG-3' & Bsr Gl & $\mathrm{N}: 251$ \\
\hline Infant B-father & (exon3) & R: 5'-TGGTTCTCCCTGAGAATGT-3' & & M: $251+234+17$ \\
\hline Infant B & H33Q & F: 5'-GAGGCCCCGCACCTGCTGCA-3' & & $\mathrm{N}: 174$ \\
\hline Infant B-mother & (exon1) & R: 5'-GCTCCGGTCTCTGAAGCTCT-3' & Pst I & M: $174+154+20$ \\
\hline
\end{tabular}




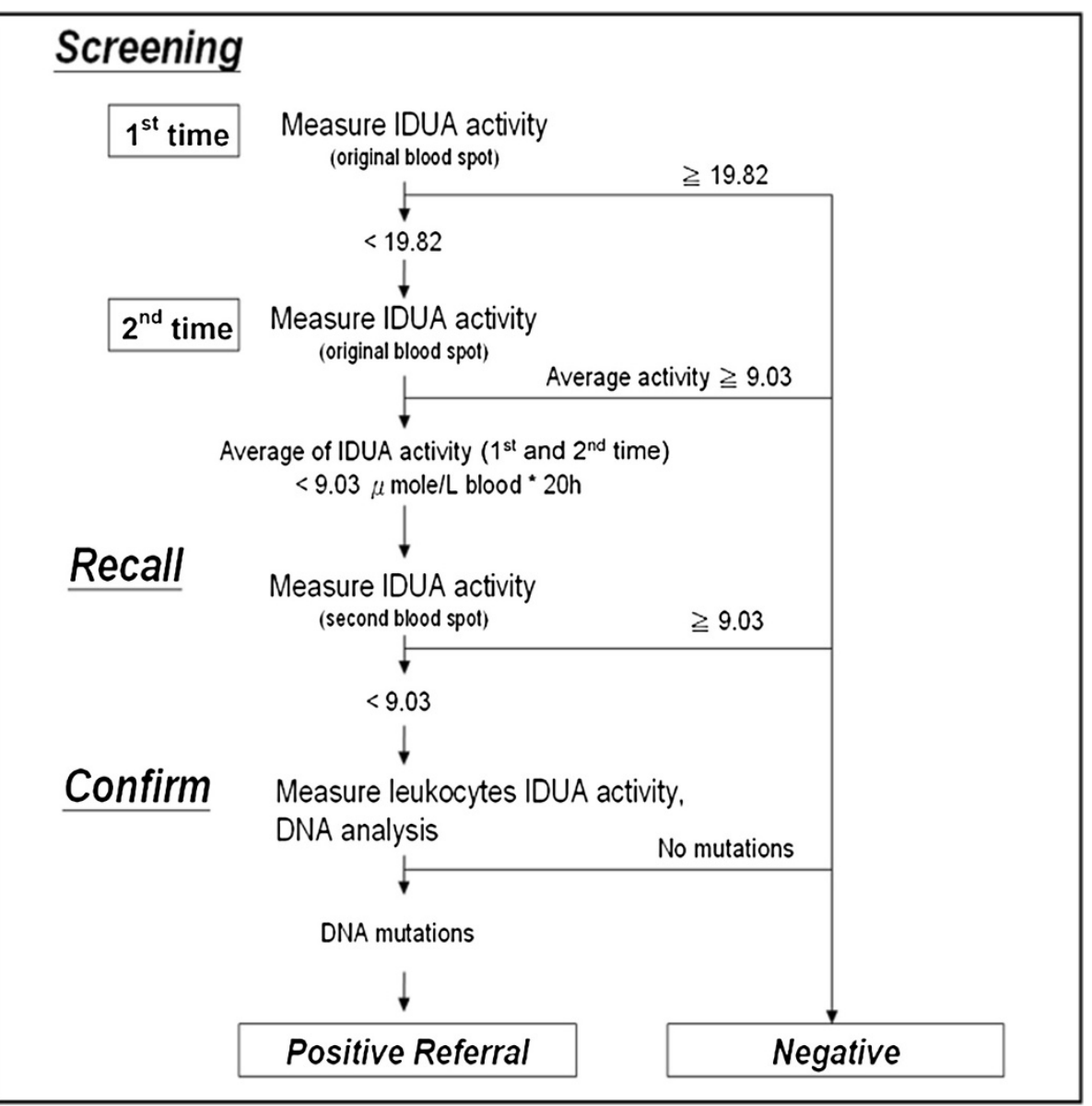

Figure 3 A diagnostic algorithm for MPS I newborn screening test.

positive samples from the highly suspicious cases including the carriers. The cut-off points of IDUA activities in DBFP by using fluorescence enzymatic assay were 19.82 and $9.03 \mu \mathrm{mol} / \mathrm{L}$ blood $20 \mathrm{~h}$ in the first and second time tests, respectively. The parents of highly suspicious infants will receive a recall notice for a second DBFP sample collection if the result of DBS fluorescence enzyme assay is less than the cut-off point, $9.03 \mu \mathrm{mol} / \mathrm{L}$ blood $^{*} 20 \mathrm{~h}$. The confirmative examinations such as leukocyte enzymatic assay and molecular DNA analysis will be performed while the second rechecked DBS fluorescence enzyme assay failed.

The IDUA activity detected by using DBS fluorescence enzyme assay is adapted for the initial diagnosis of MPS I. However, it is extremely important to guarantee the quality of DBFP samples, including collection, transport, and storage. According to the results published by Chamoles et al., there were no significant changes in enzyme activity of DBFP samples after storage for 21 days at $4^{\circ} \mathrm{C}$ or $-20^{\circ} \mathrm{C}$; in contrast, the IDUA activity will significantly decrease while the DBFP samples are stored at room temperature for the same period [21-23]. In our study, the collection, transport, and storage of DBFP samples all followed the requirements of the National Committee for Clinical Laboratory Standards protocol (NCCLS standard LA4-A4), and the quality of the DBFP was ensured.

In summary, the fluorescent enzymatic assay has the potential to be adopted for newborn screening of MPS I. The method is reliable, sensitive, validated, easy to perform, and cost-effective in measuring IDUA activity in DBFP when comparing with the tandem mass spectrometry newborn screening method. The fluorescent enzymatic assay does not require an expensive instrumentation and trained staff, and the cost per assay is about two thirds of the tandem mass spectrometry method. The incidence of MPS I in this study is about $1 / 17,643$ that might be overestimated due to the small sample size. In order to screen out more suspicious subjects actively and gauge prevalence accurately, we will continue and extend the sample numbers cooperated with other newborn screening centers in Taiwan. 


\section{Competing interest}

The authors declare that they have no competing interests.

\section{Authors' contributions}

SPL and HYL performed acquisition, statistical analysis and interpretation of data, and drafting of the manuscript. CKC participated in design of the study, interpretation of the data and helped to draft the manuscript. TJW, CHL, SFH, CCT, HLL, and JK performed biochemical analyses and revised the manuscript. CYC was responsible for patient screening. All authors read and accepted the manuscript.

\section{Acknowledgment}

The authors thank J.E. Wraith, MD for valuable comments of the manuscript, and Dar-Shong Lin, MD for proposal review. We would like to express our sincere thanks to the staffs of Clinical Laboratory and Pediatric Departments of Mackay Memorial Hospital for the sample collection. This study was supported by the research grants from the National Science Council, Taiwan (NSC-102-2314-B-195-006 and NSC-102-2314-B-195-017-MY3), Mackay Memorial Hospital (MMH-I-S-600), and Genzyme Corporation.

\section{Author details}

${ }^{1}$ Division of Genetics and Metabolism, Department of Medical Research, Mackay Memorial Hospital, Taipei, Taiwan. ${ }^{2}$ Department of Pediatrics, Mackay Memorial Hospital, Taipei, Taiwan. ${ }^{3}$ Department of Laboratory Medicine, Mackay Memorial Hospital, Taipei, Taiwan. ${ }^{4}$ Institute of Biotechnology, National Taipei University of Technology, Taipei, Taiwan. ${ }^{5}$ College of Medicine, Fu-Jen Catholic University, New Taipei City, Taiwan. ${ }^{6}$ Department of Early Childhood Care and Education, Mackay Junior College of Medicine, Nursing and Management, Taipei, Taiwan. ${ }^{7}$ Department of Medicine, Mackay Medical College, New Taipei City, Taiwan. ${ }^{8}$ Department of Biochemistry, School of Medical Laboratory Science and Biotechnology, Taipei Medical University, Taipei, Taiwan. ${ }^{9}$ Department of Pediatrics, Mackay Memorial Hospital, Hsinchu, Taiwan. ${ }^{10}$ Institute of Clinical Medicine, National Yang-Ming University, Taipei, Taiwan. ${ }^{11}$ Scientific and Medical Affairs, Genzyme Corporation, Cambridge, MA, USA.

Received: 24 June 2013 Accepted: 13 September 2013 Published: 22 September 2013

\section{References}

1. Applegarth DA, Dimmick JE, Hall JG: Organelle Diseases: Clinical features, diagnosis, pathogenesis and management, Chapman \& Hall Medical. London: Chapman \& Hall; 1997:45-97.

2. Besley GTN, Wraith JE: Lysosomal disorders. Curr Paediatri 1997, 7:128-134

3. Wraith JE: Mucopolysaccharidoses. Curr Paediatri 1996, 6:74-79.

4. Wraith JE, Clarke LA, Beck M, Kolodny EH, Pastores GM, Muenzer J, Rapoport DM, Berger Kl, Swiedler SJ, Kakkis ED, et al: Enzyme replacement therapy for mucopolysaccharidosis I: a randomized, double-blinded, placebocontrolled, multinational study of recombinant human a-L-iduronidase (laronidase). J Pediatr 2004, 144:581-588.

5. Wraith JE: The first 5 years of clinical experience with laronidase enzyme replacement therapy for mucopolysaccharidosis I. Expert Opin Pharmacother 2005, 6:489-506.

6. Lin HY, Lin SP, Chuang CK, Chen MR, Chen BF, Wraith JE: Mucopolysaccharidosis I under enzyme replacement therapy with laronidase-A mortality case with autopsy report. J Inherit Metab Dis 2005, 28:1146-1148.

7. Wraith JE, Beck M, Lane R, van der Ploeg A, Shapiro E, Xue Y, Kakkis ED, Guffon N: Enzyme replacement therapy in patients who have mucopolysaccharidosis I and are younger than 5 years: results of a multinational study of recombinant human a-L-iduronidase (laronidase). Pediatrics 2007, 120:37-46.

8. Clarke LA, Wraith JE, Beck M, Kolodny EH, Pastores GM, Muenzer J, Rapoport DM, Berger Kl, Sidman M, Kakkis ED, et al: Long-term efficacy and safety of laronidase in the treatment of mucopolysaccharidosis I. Pediatrics 2009, 123:229-240.

9. Giugliani R, Muñoz-Rojas MV, Martins AM, Valadares ER, Clarke JT, Góes JE, Kakkis ED, Worden MA, Sidman M, Cox GF: A dose-optimization trial of laronidase (Aldurazyme ${ }^{\oplus}$ ) in patients with mucopolysaccharidosis I. Mol Genet Metabol 2009, 96:13-19.
10. Kakkis ED, Muenzer J, Tiller GE, Waber L, Belmont J, Passage M, Izykowski B, Phillips J, Doroshow R, Walot I, et al: Enzyme replacement therapy in mucopolysaccharidosis I. N Engl J Med 2001, 344:182-188.

11. Sifuentes M, Doroshow R, Hoft R, Mason G, Walot I, Diament M, Okazaki S, Huff K, Cox GF, Swiedler SJ, et al: A follow up study of MPS I patients treated with laronidase enzyme replacement therapy for 6 years. Mol Genet Metab 2007, 90:171-180.

12. De Ru MH, van der Tol L, Van Vlies N, Bigger BW, Hollak CE, ljlst L, Kulik W, Van Lenthe H, Saif MA, Wagemans T, van der Wal WM, Wanders RJ, Wijburg FA: Plasma and urinary levels of dermatan sulfate and heparin sulfate derived disaccharides after long-term enzyme replacement therapy (ERT) in MPS I: correlation with the timing of ERT and with total urinary excretion of glycosaminoglycans. J Inherit Metab Dis 2013, 36:247-255.

13. Peters C, Balthazor M, Shapiro EG, King RJ, Kollman C, Hegland JD, Henslee-Downey J, et al: Outcome of unrelated donor bone marrow transplantation in 40 children with Hurler syndrome. Blood 1996, 87:4894-4902.

14. Muenzer J, Wraith JE, Clarke LA, International Consensus Panel on Management and Treatment of Mucopolysaccharidosis I: Mucopolysaccharidosis I: management and treatment guidelines. Pediatrics 2009, 123:19-29.

15. Boelens JJ, Prasad VK, Tolar J, Wynn RF, Peters C: Current international perspectives on hematopoietic stem cell transplantation for inherited metabolic disorders. Pediatr Clin North Am 2010, 57:123-145.

16. De Ru MH, Boelens JJ, Das AM, Jones SA, van der Lee JH, Mahlaoui N, et al: Enzyme replacement therapy and/or hematopoietic stem cell transplantation at diagnosis in patients with mucopolysaccharidosis type I: results of a European consensus procedure. Orphanet J Rare Dis 2011, 6:55. doi:10.1186/1750-1172-6-55.

17. Gabrielli O, Clarke LA, Bruni S, Coppa GV: Enzyme-replacement therapy in a 5-month-old boy with attenuated presymptomatic MPS I: 5-year follow-up. Pediatrics 2010, 125:e183-e187.

18. Wang RY, Cambray-Forker EJ, Ohanian K, Karlin DS, Covault KK, Schwartz PH, Abdenur JE: Treatment reduces or stabilizes brain imaging abnormalities in patients with MPS I and II. Mol Genet Metab 2009, 98:406-411.

19. Lin HY, Lin SP, Chuang CK, Niu DM, Chen MR, Tsai FJ, Chao MC, Chiu PC, Lin SJ, Tsai LP, Hwu WL, Lin JL: Incidence of the mucopolysaccharidoses in Taiwan, 1984-2004. Am J Med Genet A 2009, 149A:960-964.

20. NCCLS: Blood Collection on Filter Paper for Newborn Screening Programs; Approved Standard_Fourth Edition, NCCLS document LA4-A4 (ISBN 1-56238503-8). 940 West Valley Road, Suite 1400, Wayne, Pennsylvania 19087-1898 USA: NCCLS; 2003

21. De Jesus VR, Zhang XK, Keutzer J, Bodamer OA, Mühl A, Orsini JJ, Caggana M, Vogt RF, Hannon WH: Development and evaluation of quality control dried blood spot materials in newborn screening for lysosomal storage disorders. Clin Chem 2009, 55:158-164.

22. Chamoles NA, Blanco M, Gaggioli D: Diagnosis of a-L-Iduronidase deficiency in dried blood spots on filter paper: the possibility of newborn diagnosis. Clin Chem 2001, 47:780-781.

23. Chamoles NA, Blanco MB, Gaggioli D, Casentini C: Hurler-like phenotype: enzymatic diagnosis in dried blood spots on filter paper. Clin Chem 2001, 47:2098-2102.

24. Chuang CK, Lin SP, Chung SF: Diagnostic screening for mucopolysaccharidoses by the dimethylmethylene blue method and two dimensional electrophoresis. Zhonghua Yi Xue Za Zhi (Taipei) 2001, 64:15-22.

25. Chuang CK, Lin SP, Lee SJ, Wong TJ: MPS screening methods, the Berry spot and acid turbidity tests, cause a high incidence of false-negative results in Sanfilippo and Morquio syndromes. J Clin Lab Anal 2002, 16:253-258.

26. Mabe P, Valiente A, Soto V, Cornejo V, Raimann E: Evaluation of reliability for urine mucopolysaccharidosis screening by dimethylmethylene blue and Berry spot tests. Clin Chim Acta 2004, 345:135-140.

27. Sun L, Li C, Song X, Zheng N, Zhang H, Dong G: Three novel a-Liduronidase mutations in 10 unrelated Chinese mucopolysaccharidosis type I families. Genet Mol Biol 2011, 34:195-200.

28. Wang X, Zhang W, Shi H, Qiu Z, Meng Y, Yao F, Wei M: Mucopolysaccharidosis I mutations in Chinese patients: identification of 27 novel mutations and 6 cases involving prenatal diagnosis. Clin Genet 2012, 81:443-452.

29. Murphy AM, Lambert D, Treacy EP, O'Meara A, Lynch SA: Incidence and prevalence of mucopolysaccharidosis type 1 in the Irish republic. Arch Dis Child 2009, 94:52-54. 
30. Moore $\mathrm{D}$, Connock MJ, Wraith $\mathrm{E}$, Lavery $\mathrm{C}$ : The prevalence of and survival in Mucopolysaccharidosis I: Hurler, Hurler-Scheie and Scheie syndromes in the UK. Orphanet J Rare Dis 2008, 3:24.

31. Meikle PJ, Hopwood JJ, Clague AE, Carey WF: Prevalence of lysosomal storage disorders. JAMA 1999, 281:249-254.

32. Nelson J: Incidence of the mucopolysaccharidoses in Northern Ireland. Hum Genet 1997, 101:355-358.

33. Lowry RB, Renwick DH: Relative frequency of the Hurler and Hunter syndromes. N Engl J Med 1971, 284:221-222.

34. Scott CR, Elliott S, Buroker N, Thomas LI, Keutzer J, Glass M, Gelb MH, Turecek F: Identification of infants at risk for developing fabry, pompe, or mucopolysaccharidosis-I from newborn blood spots by tandem mass spectrometry. J Pediatr 2013, 163:498-503.

35. Poorthius BJ, Wevers RA, Kleijer WJ, Groener JE, De Jong JG, Van Weely S, et al: The frequency of lysosomal storage diseases in The Netherlands. Hum Genet 1999, 105:151-156.

36. Parkinson-Lawrence E, Fuller M, Hopwood JJ, Meikle PJ, Brooks DA: Immunochemistry of lysosomal storage disorders. Clin Chem 2006, 52:1660-1668.

37. Li Y, Scott CR, Chamoles NA, Ghavami A, Pinto BM, Turecek F, Gelb MH: Direct multiplex assay of lysosomal enzymes in dried blood spots for newborn screening. Clin Chem 2004, 50:1785-1796.

38. Zhang XK, Elbin CS, Chuang WL, Cooper SK, Marashio CA, Beauregard C, Keutzer JM: Multiplex enzyme assay screening of dried blood spots for lysosomal storage disorders by using tandem mass spectrometry. Clin Chem 2008, 54:1725-1728.

39. Blanchard S, Sadilek M, Scott CR, Turecek F, Gelb MH: Tandem mass spectrometry for the direct assay of lysosomal enzymes in dried blood spots: application to screening newborns for mucopolysaccharidosis I. Clin Chem 2008, 54:2067-2070.

doi:10.1186/1750-1172-8-147

Cite this article as: Lin et al: A pilot newborn screening program for Mucopolysaccharidosis type I in Taiwan. Orphanet Journal of Rare Diseases 2013 8:147.

\section{Submit your next manuscript to BioMed Central and take full advantage of:}

- Convenient online submission

- Thorough peer review

- No space constraints or color figure charges

- Immediate publication on acceptance

- Inclusion in PubMed, CAS, Scopus and Google Scholar

- Research which is freely available for redistribution 